\title{
Perceptions Of Unemployed Workers: Unemployment Duration, Volunteerism, And Age
}

Ted H. Shore, Ph.D., California State University, San Marcos, USA Armen Tashchian, Ph.D., Kennesaw State University, USA

\begin{abstract}
This study investigated the effects of unemployment duration, volunteerism and age on perceptions of unemployed job candidates. An experimental design was employed in which participants judged fictitious resumes of unemployed candidates. We found that candidates unemployed for 18 months were viewed as less qualified and would be less likely to be interviewed and hired than those unemployed for 6 or 12 months at all age levels $(30,40,50)$ studied. Candidates who had performed volunteer work (career-or non-career-related) would be more likely to be interviewed and hired than those who had not volunteered. Implications of the findings were discussed.
\end{abstract}

Keywords: Unemployed Workers; Unemployment Duration

\section{INTRODUCTION}

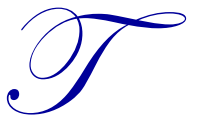

he current economic crisis has brought an onslaught of corporate layoffs and a dramatic increase in the rate of unemployment. For many individuals job loss is a stressful life event characterized by financial hardship, anxiety, and loss of social networks/self-esteem. Recent research has focused on identifying variables linked with reemployment success (e.g., Kanfer, et al., 2006). The purpose of this study is to examine the impact of three factors that can potentially affect a displaced worker's likelihood of gaining reemployment - unemployment duration, volunteer work experience and age. An experimental study was conducted to address the specific research questions.

\section{UNEMPLOYMENT DURATION}

In recent months, the popular media has reported that an increasing number of employers are unwilling to hire unemployed job seekers (or those who have been unemployed beyond a certain length of time). For example, one company reports that they are only willing to consider "happily employed" applicants, while another will not consider applicants who have been unemployed for more than nine months. The EEOC recently began to investigate employers who refuse to hire unemployed applicants as a form of discrimination. The EEOC argues that using unemployment as a selection criterion has a disparate impact against minorities and older individuals who are more likely to be unemployed than younger non-minority workers (HR Source, 2011). The use of a restrictive hiring standard based on employment status is distressing; the unwillingness to hire unemployed job applicants has the potential to create a large cadre of permanently unemployed individuals.

These reports raise questions about the stigma associated with being unemployed. The unemployed applicant may be viewed as "damaged goods" despite the fact that many individuals have become unemployed solely due to adverse economic conditions. Employers may make a variety of negative attributions about unemployed applicants (e.g., outdated job skills, poor interpersonal skills). Furthermore, these negative attributions may become stronger the longer an individual has been unemployed. 
Minimal research has examined the effects of unemployment duration on the likelihood of gaining reemployment. However, a few studies have shown that the probability of reemployment declines as the length of one's unemployment increases (McGregor, 1978). Three factors have been attributed to the causal link between unemployment duration and the likelihood of reemployment. First, prolonged unemployment causes physical and mental deterioration, making an applicant less attractive to prospective employers over time. Second, unsuccessful applicants become discouraged over time and look less intensively for work. Third, employers may use restrictive hiring standards in which employment status is used as a selection criterion (McGregor, 1978). That is, after a certain length of unemployment, employers may view the unemployed individual as "unfit" for work.

There has been scant research on the use of restrictive hiring standards. Most research on reemployment has focused on demographic and other personal characteristics. For example, studies have consistently shown that older workers (i.e., those over age 55) are more likely to be displaced (Gardner, 1995), have longer periods of unemployment (Lippmann, 2008), are less likely to become reemployed and suffer greater earnings loss (Koeber \& Wright, 2001; Smith \& Rubin, 1997) than younger displaced workers. McGregor (1978) found that restrictive hiring standards (i.e., unemployment duration) was causally linked with the probability of gaining reemployment even after controlling for age, job skills and marital status. Furthermore, the probability of becoming reemployed begins to decline after being unemployed for more than three months, and after 6 months declines significantly (McGregor, 1978), suggesting that employers do employ restrictive hiring standards based on unemployment status. Thus, we hypothesized that:

H1: There is a negative relationship between applicant attractiveness and the length of time an individual has been unemployed due to the use of a restrictive hiring standard.

H2: There is a negative relationship between applicant age and the likelihood of gaining reemployment.

\section{VOLUNTEERISM}

Recent news reports on discrimination against the unemployed suggest that performing volunteer work is a potential way to increase the likelihood of gaining employment (Today Show, 2011). Many types of organizations utilize volunteers including medical, educational institutions, social service agencies and community organizations (Phillips \& Phillips, 2000). Although relatively little research has focused on volunteerism as a way to enhance employment prospects, some scholars argue that career development is a primary goal of individuals who perform volunteer work (e.g., Ellis, 1993; Haski-Leventhal, 2008; Zakour, 1994). Volunteer work has the potential to increase one's employability in multiple ways. First, volunteer work may enable an individual to expand their range of professional skills. Volunteers work in a variety of organizational roles, providing opportunities to gain supervisory, leadership, decision-making, budgeting and communication skills (Phillips \& Phillips, 2000). Ellis (1993) argues that volunteerism provides a ready opportunity to gain business experience as volunteers may have greater opportunity in choosing the type of work performed than paid workers. Thus, skills gained through volunteerism should increase the likelihood of obtaining a paid position (Haski-Leventhal, 2008).

Beyond gaining job skills, volunteer work may enhance one's employment prospects by creating a generally favorable impression about an individual. Surveys of desired job skills/qualities reveals that decisionmaking, honesty, integrity, communication skills, problem-solving skills, teamwork, interpersonal skills and a strong work ethic are desired by employers. Volunteer work may result in an attribution of these favorable personal qualities by many employers. Research has indeed shown that volunteerism is positively related to having altruistic personality traits (Pearce, 1993). Thus, an individual who has shown a willingness to donate their time as a volunteer worker is likely to be perceived as a good potential corporate citizen.

According to the functional theory of motivation (Clary, et al., 1998), six functional motives for volunteer work have been identified including social, career development, learning opportunity (i.e., skill acquisition), values (i.e., altruism), self-esteem, and guilt reduction (e.g., Greenslade \& White, 2005; Houle, Sagarin \& Kaplan 2005;). In particular, career and skills development has been identified as a major goal of volunteerism (Finkelstein, Penner \& Brannick, 2005; Phillips \& Phillips, 2010). Peloza \& Hassay (2006) investigated the motives for employees doing volunteer work on behalf of their current organization and found that employees are motivated by the potential for impression management as well as gaining professional and interpersonal skills. Similarly, Peterson (2004) found 
that employees participate in volunteer activities for both altruistic and egoistic reasons (e.g., personal skill development).

Research on organizational citizenship behavior (OCB) suggests that employers value volunteer work. Borman and Motowidlo (1993) describe organizational citizenship behavior (OCB) as "volunteering for activities beyond a person's formal job expectations". Research has established a link between OCB and supervisor performance rankings (Vanscotter \& Motowidlo, 2000), suggesting that volunteer work performed by unemployed job candidates should create a favorable impression upon prospective employers, enhancing their likelihood of obtaining paid employment.

In summary, volunteer experience has the potential to benefit one's career in two ways. First, volunteer workers may gain job-relevant skills/competencies. Second, performing volunteer work (of any type) may create an attribution by others of generally favorable personal qualities. Although prior research has not determined which of these factors has the greater impact on one's career prospects, it can be reasoned that the effects are additive. That is, career-relevant volunteer work has the dual benefit of providing an opportunity to enhance one's professional skills as well as creating a generally favorable impression of oneself. By contrast, the potential benefit of non-career relevant volunteer experience should be largely limited to favorable impression management. Thus, career-relevant volunteer experience should be greater in terms of attracting interest from prospective employers than non-careerrelated volunteerism. Therefore, we hypothesized that:

H3: Job applicants with career-relevant volunteer work experience would be more attractive to prospective employers and those with no volunteer work experience the least attractive to employers.

\section{METHOD}

\section{Participants}

Two hundred and seventy undergraduate business students (49\% male; 51\% female) from a medium size state university in the west served as participants. The mean age of participants was 26 years and they had an average of 4 years of full-time work experience.

\section{Procedure}

Data were collected in human resource management classes. Each participant was given a booklet which included instructions, a fictitious resume and questionnaire. Participants were told to assume they were reviewing the resume of a job candidate for the position of Financial Analyst. They were told their job candidate had been unemployed for either 6,12 or 18 months and was either age 30, 40 or 50. Participants were instructed to carefully review their resume and then answer a series of questions.

\section{Experimental Design and Dependent Measures}

A $3 \times 3 \times 3$ factorial design was employed in which the independent variables were unemployment duration $(6,12$ or 18 months), candidate age $(30,40$ or 50$)$ and volunteer work experience (none, career-related, non-careerrelated). The dependent variables were ratings using a 5-point Likert scale on how likely you would be to interview and hire the candidate (based on their resume) and how qualified the candidate is for the position.

Resumes. A total of 27 different resumes were produced using various combinations of experimental conditions. All candidates had spent their careers working in the financial services industry and had a career objective of obtaining a position as a financial analyst. One-third of the resumes indicated that the candidate had been doing career-related volunteer work since becoming unemployed (providing financial services for a non-profit organization). One-third of resumes indicated the candidate had been doing non-career volunteer work (for a homeless shelter) and one-third of resumes made no mention of volunteer work. All resumes used the name Pat Anderson; a gender neutral name was selected to avoid introducing gender into the experimental design. 
One-third of the resumes indicated the candidate had been unemployed for 6 months, one-third for 12 months and one-third for 18 months. Finally, the dates of graduation from college were consistent with the candidate's age (revealed in the instructions on each booklet).

Post-Experiment Questionnaire. After reviewing their resume, participants completed a questionnaire consisting of ratings on the dependent variables, demographic data and manipulation checks. After collecting all booklets, participants were debriefed.

\section{RESULTS}

\section{Manipulation Checks}

All manipulation check items were rated on 5 -point scale $(1=$ strongly agree, $5=$ strongly disagree $)$. The experimental manipulation determined if respondents considered age, volunteer work experience and unemployment duration when evaluating the candidate. Subjects responded to the statement "In judging the candidate's resume, I considered their age," with a mean of 2.81. The mean response to the question, "In judging the candidate's resume, I considered whether they had done volunteer work," was 2.73, and to the statement "In judging the candidate's resume, I considered how long they had been unemployed," with a mean of 2.36. These results indicate that age, volunteer work experience and unemployment duration were considered when evaluating the resumes.

\section{Main Effects}

The means and standard deviations for all experimental conditions are shown in Table 1. Table 2 presents the ANOVA results for all three dependent variables (candidate qualifications, interview the candidate, and hire the candidate).

Table 1

Mean and Standard Deviations for Experimental Conditions

Dependent Measures

\begin{tabular}{ccccccccc} 
& \multicolumn{2}{c}{ Grant a Job Interview } & & \multicolumn{2}{c}{ Candidate Highly Qualified } & & \multicolumn{2}{c}{ Hire the Candidate } \\
& Mean & SD & & Mean & SD & & Mean & SD \\
\hline Months Unemployed & & & & & & & \\
6 & 1.89 & 0.77 & & 2.09 & 0.77 & & 3.34 & 1.01 \\
12 & 1.93 & 0.96 & & 2.14 & 0.93 & & 3.23 & 0.98 \\
18 & 2.54 & 0.91 & & 3.23 & 0.84 & & 3.87 & 0.99 \\
Age & & & & & & \\
30 & 2.35 & 1.08 & & 2.41 & 0.89 & & 3.47 & 0.95 \\
40 & 2.42 & 0.73 & & 1.81 & 0.71 & & 3.11 & 0.73 \\
50 & 2.21 & 0.77 & & 1.67 & 0.81 & & 3.01 & 1.04 \\
Volunteer Work & & & & & & \\
Career-related & 1.89 & 0.85 & & 2.12 & 0.69 & & 2.87 & 0.87 \\
Noncareer-related & 1.92 & 0.81 & & 2.09 & 0.91 & & 2.76 & 0.89 \\
No Volunteer Work & 2.43 & 0.97 & & 2.18 & 0.94 & & 3.52 & 0.94 \\
\hline
\end{tabular}


Table 2

Analysis of Variance for Candidate Attractiveness Measures

\begin{tabular}{|c|c|c|c|c|c|c|c|}
\hline \multirow[b]{3}{*}{ Main Effects } & \multirow[b]{3}{*}{$d f$} & \multicolumn{6}{|c|}{ Dependent Measures } \\
\hline & & \multicolumn{2}{|c|}{ Grant a Job Interview } & \multicolumn{2}{|c|}{ Candidate Highly Qualified } & \multicolumn{2}{|c|}{ Hire the Candidate } \\
\hline & & $\mathrm{F}$ & $p$ & $\mathrm{~F}$ & $P$ & $\mathrm{~F}$ & $P$ \\
\hline Months Unemployed & 2 & 5.521 & 0.005 & 8.832 & 0.001 & 6.884 & 0.001 \\
\hline Age & 2 & 1.731 & 0.179 & 12.921 & 0.001 & 3.617 & 0.027 \\
\hline Volunteer Work & 2 & 4.333 & 0.015 & 2.053 & 0.131 & 3.467 & 0.033 \\
\hline \multicolumn{8}{|l|}{ Two Way Interactions } \\
\hline Months Unemployed x Age & 4 & 0.451 & 0.772 & 0.633 & 0.532 & 1.697 & 0.153 \\
\hline Months Unemployed $x$ Volunteer Work & 4 & 1.189 & 0.316 & 1.042 & 0.355 & 1.405 & 0.234 \\
\hline Age $x$ Volunteer Work & 4 & 1.067 & 0.387 & 0.467 & 0.754 & 0.549 & 0.579 \\
\hline \multicolumn{8}{|l|}{ Three Way Interaction } \\
\hline Months Unemployed $x$ Age $x$ Volunteer Work & 8 & 0.286 & 0.887 & 0.755 & 0.643 & 1.311 & 0.241 \\
\hline
\end{tabular}

The first hypothesis predicted an inverse relationship between unemployment duration and applicant attractiveness. For each dependent measure the main effects for months unemployed was statistically significant $\left(\mathrm{F}_{\text {grant interview }}=5.52, p<0.01, \mathrm{~F}_{\text {candidate qualified }}=8.83, p<0.01\right.$, and $\left.\mathrm{F}_{\text {hire candidate }}=6.88, p<0.01\right)$. Thus, we found that applicants who were unemployed for 6 or 12 months were viewed as more qualified $\left(\mathrm{M}_{6 \text { months }}=2.09, \mathbf{M}_{12 \mathrm{months}}=\right.$ $\left.2.14 v s \mathrm{M}_{18 \text { months }}=3.23\right)$, and more likely to be interviewed $\left(\mathrm{M}_{6 m o n t h s}=1.89, \mathrm{M}_{12 \mathrm{months}}=1.93 \mathrm{vs} \mathrm{M}_{18 \mathrm{monts}}=2.54\right)$ and hired $\left(\mathrm{M}_{\text {6months }}=3.34, \mathrm{M}_{12 \text { months }}=3.23\right.$ vs $\left.\mathrm{M}_{18 \text { months }}=3.87\right)$ than those who had been unemployed for 18 months. Interestingly, there was no interaction between unemployment duration, age or volunteer work. Thus, although there were no significant differences for unemployment duration of 6 and 12 months, the hypothesis was supported overall.

Hypothesis two predicted a negative relationship between applicant age and applicant attractiveness. Contrary to expectations, we found that older applicants were more likely to be hired than younger job candidates $\left(\mathrm{M}_{50 \text { years }}=3.01, \mathrm{M}_{40 \text { years }}=3.11\right.$ vs $\left.\mathrm{M}_{30 \text { years }}=3.47, \mathrm{~F}_{\text {hire candidate }}=3.62, p<0.05\right)$. Older candidates were also viewed as more qualified $\left(\mathrm{M}_{50 \text { years }}=1.67, \mathrm{M}_{40 \text { years }}=1.81\right.$ vs $\left.\mathrm{M}_{30 \text { years }}=2.41, \mathrm{~F}_{\text {candidate qualified }}=12.92, p<0.01\right)$ which is not surprising since candidates had 10, 20 and 30 years of professional work experience for ages 30 , 40, \& 50, respectively. However, age had no effect on the likelihood of receiving a job interview $\left(\mathrm{F}_{\text {grant interview }}=1.73, p<0.17\right)$.

Hypothesis three predicted that candidates who had performed career-related volunteer work would be the most attractive and those who had performed no volunteer work the least attractive candidates. As expected we found that the candidates who had not performed volunteer work were least likely to be interviewed $\left(\mathrm{M}_{j o b}\right.$ related $=$ $\left.1.89, \mathrm{M}_{\text {job unrelated }}=1.92, \mathrm{M}_{\text {no volunteer work }}=2.43, \mathrm{~F}_{\text {grant interview }}=4.33, p<0.01\right)$ and hired $\left(\mathrm{M}_{\text {job related }}=2.87, \mathrm{M}_{\text {job unrelated }}=\right.$ $\left.2.76, \mathrm{M}_{\text {no volunteer work }}=3.52, \mathrm{~F}_{\text {hire candidate }}=3.47, p<0.05\right)$. Contrary to expectations, there was no difference between candidates who had performed career- versus non-career-related volunteer work in terms of their likelihood of being interviewed and hired. Furthermore, we also found no differences in perceived qualifications as a function of volunteerism $\left(\mathrm{F}_{\text {volunteer } \text { work }}=2.05, p<0.13\right)$. Thus, Hypothesis three received partial support.

\section{DISCUSSION}

This study investigated the effects of several factors on the perceptions of unemployed workers. We found that the longer an individual has been unemployed the less attractive he/she is as a job candidate. Individuals unemployed for 18 months were viewed as less qualified, and were less likely to be granted an interview and hired (based on their resume) than those unemployed for 6 or 12 months. This result was consistent across all age groups $(30,40,50)$ studied and regardless of whether the candidate had performed volunteer work while unemployed.

Our findings are consistent with field studies showing that unemployed workers face increasing difficulty gaining re-employment the longer they have been unemployed. For example, McGregor (1978) reported that after being unemployed for 6 months, the likelihood of gaining re-employment declines significantly. We found that the 
likelihood of obtaining re-employment declines after a longer duration of unemployment than was found in prior studies. One possible reason for this is that our data were collected during a time of relatively high unemployment (2011-2012) when being unemployed for 12-18 months was not unusual.

Field studies demonstrating the link between unemployment duration and likelihood of re-employment leave unresolved the reason for this relationship. One view is that employers employ a restrictive hiring standard based on unemployment duration. This may occur due to negative attributions made about the (long-term) unemployed candidate (e.g., personality traits, outdated job skills). Alternative explanations are that as time passes the unemployed worker becomes discouraged and puts forth less effort to find employment, as well as being less attractive to prospective employers due to physical/emotional decline. Our experimental study suggests that use of a restrictive hiring standard accounts, at least in part, for the difficulty encountered by long-term unemployed individuals. A large number of judges who evaluated fictitious resumes in our study were much less inclined to interview and hire candidates who had been unemployed for 18 months as contrasted with those unemployed for 6 or 12 months. Informal discussions with these judges revealed that they ascribed various negative attributes to the candidate unemployed for 18 months, including poor interpersonal skills, laziness and poor/outdated job skills.

Our experimental finding is consistent with the recent trend that employers are reluctant or even unwilling to hire long-term unemployed workers. Although this bias has likely existed for a long time, it is only recently that employers have revealed their bias when advertising vacant job positions. For example, it has recently been reported that some employers are only willing to consider "happily employed" candidates and others have stated their unwillingness to consider candidates unemployed for more than 9 months. Debate has begun as to the legality of such employment practices. The Obama administration and the EEOC have begun to investigate these restrictive hiring practices as a form of employment discrimination. Some legal scholars have argued that restrictive hiring standards based on employment status are not a violation of law since employment status is not an immutable characteristic (like age or race) and thus does not constitute disparate treatment. However, others have argued that making hiring decisions based on employment status has a disparate impact on racial minorities since a greater proportion of unemployed workers are minorities.

We also found that candidates who performed volunteer work while unemployed were viewed more favorably than those who did no volunteer work. Furthermore, candidates who performed career-related or noncareer-related volunteer work were viewed as equally attractive. Interestingly, job candidates who had performed volunteer work were more likely to be granted a job interview and hired, but were not seen as more qualified than candidates who had not done volunteer work. These results suggest that performing volunteer work serves to enhance a candidate's attractiveness due to perceptions that he/she possesses desirable personal attributes (e.g., citizenship) rather than because of perceptions of technical job qualifications/skills. This finding is consistent with prior research suggesting that volunteerism creates a favorable impression on others (e.g., Peloza \& Hassay, 2006).

However, our finding conflicts with the view held by some scholars that volunteer work increases candidate attractiveness by enhancing job skills (Finkelstein, et al., 2005; Haski-Leventhal, 2008; Phillips \& Phillips, 2000). A practical implication of this finding is that an unemployed worker can enhance their reemployment prospects by doing volunteer work that is either career or non-career-related. It may be more feasible for an individual to perform non-career volunteer work since these opportunities may be readily available through school and civic associations and can be done during non-business hours (e.g., evening, weekends). Our research suggests that prospective employers likely ascribe various favorable characteristics to candidates who perform volunteer work (i.e., good citizen, hard worker, dedicated). Although candidates who have not done volunteer work may possess these traits, the volunteer worker has demonstrated these characteristics through their behavior. This finding suggests that unemployed individuals can improve their chances of re-employment by performing volunteer work in their community.

Contrary to expectations, we found that older job candidates were viewed as more attractive than young candidates. Older candidates were perceived as more qualified and were more likely to be hired. This conflicts with some past research that reported bias against older workers (Gardner, 1995; Lippmann, 2008). Our finding is particularly interesting given the relatively young age of our study participants who judged the resumes. 
This study had several limitations. First, we employed an experimental design in which fictitious resumes were judged by college students, raising questions about the generalizability of our findings to actual work settings. However, most of our sample had work experience and could thus relate to the issues depicted in the study. The magnitude our experimental effects may have been less than would be obtained in an actual work setting. For example, individuals with more work experience may be more likely to view career-related volunteer experience as more valuable than non-career volunteer work; our sample viewed both types of volunteer experience as equally valuable. Each participant in our study judged a single resume, whereas in actual work settings multiple candidates are often compared with one another. Thus, differences between candidates on such issues as unemployment duration and volunteer work experience become particularly evident.

In summary, this study provides empirical evidence that long-term unemployed job candidates are perceived as less attractive than those unemployed for lesser periods of time, regardless of age. Furthermore, job candidates of any age who perform either career- or non-career related volunteer work are viewed as more attractive than those who perform no volunteer work. Thus, our findings suggest that unemployed workers can enhance their likelihood of becoming re-employed by performing any type of volunteer work.

\section{AUTHOR INFORMATION}

Ted Shore received his Ph.D. in industrial and organizational psychology from Colorado State University. He is Professor of Management California State University, San Marcos, USA. His work has been published in a variety of journals including Academy of Management Journal, Journal of Applied Psychology, Personnel Psychology, Journal of Organizational Behavior, Journal of Vocational Behavior, and Journal of Applied Social Psychology. E-mail: tshore@csusm.edu

Armen Tashchian is Professor of Marketing in the Coles College of Business at Kennesaw State University, USA. He received his Ph.D. in Marketing from the University of Texas in 1980. He has published in numerous academic journals including Journal of Marketing, Journal of Marketing Research, and the Journal of Academy of Marketing Science. E-mail: atashchi@kennesaw.edu (Corresponding Author)

\section{REFERENCES}

1. Borman, W.C., \& Motowidlo, S.J. (1993). Expanding the criterion domain to include elements of contextual performance. In N. Schmitt and W.C. Borman (eds.). Personality Selection (Jossey-Bass, San Francisco), pp. 71-98.

2. $\quad$ Clary, E.G., Snyder, M., Ridge, R.D., Copeland, J., Stukas, A.A., \& Haugen, J. (1998). Understanding and assessing the motivations of volunteers: A functional approach. Journal of Personality and Social Psychology, 74, 1516-1530.

3. Ellis, J.R. (1993). Volunteerism as an enhancement to career development. Journal of Employment Counseling, 30, 127-132.

4. Finkelstein, M.A., Penner, L.A., \& Brannick, M.T. (2005). Motive, role identity and prosocial personality as predictors of volunteer activity. Social Behavior and Personality, 33, 403-418.

5. Gardner, J.M., (1995). Worker displacement: A decade of change. Monthly Labor Review, 118, 45-67.

6. Greenslade, J.J., \& White, K.M. (2005). The prediction of above-average participation in volunteerism: A test of the theory of planned behavior and the Volunteers Function Inventory in older Australian adults.

7. Haski-Leventhal, D. (2008). Altruism and volunteerism: The perceptions of altruism in four disciplines and their impact on the study of volunteerism. Journal for the Theory of Social Behavior, 39, 271-299.

8. $\quad$ HR Source (2011).

9. Houle, B.J., Sagarin, B.J., \& Kaplan, M.F. (2005). A functional approach to volunteerism: Do volunteer motives predict task preference? Basic and Applied Psychology, 27, 337-344.

10. Koeber, C., \& Wright, D.W. (2001). Age bias in worker displacement: How industrial structure shapes the job loss and earnings decline of older Americans. Journal of Socioeconomics, 30, 343-352.

11. Lippmann, S. (2008). Rethinking risk in the new economy: Age and cohort effects on unemployment and re-employment. Human Relations, 61, 1259-1292. 
12. McGregor, A. (1978). Unemployment duration and re-employment probability. The Economic Journal, 88, 693-706.

13. Oesterle, S., Kirkpatricl, M., \& Mortimer, J.T. (2004). Volunteerism during the transition to adulthood: A life course perspective. Social Forces, 82, 1123-1149.

14. $\quad$ Pearce, J.L. (1993). Volunteers: The organizational behavior of unpaid workers. London \& New York: Routledge.

15. Peloza, J, \& Hassay, D.N. (2006). Intra-organizational volunteerism: Good soldiers, good deeds and good politics. Journal of Business Ethics, 64, 357-379.

16. Peterson, D. (2004). Recruitment strategies for encouraging participation in corporate volunteer programs. Journal of Business Ethics, 49, 371-386.

17. Phillips, A.S. \& Phillips, C.R. (2000). Using skills gained through volunteerism in job searches: A workable strategy. Journal of Business and Psychology, 14, 573-577.

18. Phillips, L.C. \& Phillips, M.H. (2010). Volunteer motivation and reward preference: An empirical study of volunteerism in a large, not-for-profit organization. SAM Advanced Management Journal, 12-39.

19. Smith, B.T., \& Rubin, B.A., (1997). From displacement to reemployment: Job acquisition in the flexible economy. Social Science Research, 26, 292-308.

20. Snyder, M., Omoto, A.M., \& Lindsay, J.J. (2004). Sacrificing time and effort for the good of others: The benefits and costs of volunteerism. In A. Miller (Ed.) The social psychology of good and evil, pp. 444-468. New York: Guilford.

21. Today Show (August, 18, 2011).

22. Van Scotter, J.R. \& Motowidlo, S.J. (2000). Effects of task performance and contextual performance on systematic rewards. Journal of Applied Psychology, 85, 526-353.

23. Zakour, M.J. (1994). Measuring career-development volunteerism: Guttman scale analysis using Red Cross volunteers. Journal of Social Service Research, 19, 103-120. 